\title{
The Effect of Packaging Attributes on Consumer Buying Decision Behavior in Major Commercial Cities in Ethiopia
}

\author{
Getie Andualem Imiru ${ }^{1}$ \\ ${ }^{1}$ Addis Ababa University-School of Commerce, Ethiopia \\ Correspondence: Getie Andualem Imiru, Addis Ababa University-School of Commerce, Ethiopia. E-mail: \\ get_aiwo@yahoo.com
}

Received: October 23, $2017 \quad$ Accepted: November 13, $2017 \quad$ Online Published: November 27, 2017

doi:10.5539/ijms.v9n6p43 URL: http://doi.org/10.5539/ijms.v9n6p43

\begin{abstract}
Due to increasing self-service and changing consumers' lifestyle, the interest in package as a tool of sales promotion and stimulator of impulsive buying behavior is growing increasingly. The objective of this survey was to examine the effect of packaging attributes on consumer buying decision behavior. A total of 384 questionnaires were distributed to standard supermarkets in Addis Ababa and other major cities in Ethiopia. Only 369 questionnaires were returned at the end of the data collection process, which gave the response rate of 96 per cent. However, during the data cleaning only 362 were usable and used for the subsequent statistical analysis. Data collected were analyzed using correlation and regression. Innovation has the strongest effect on cereal food purchase decision (0.392) followed by printed information (0.193), background image (0.168) and font size (0.168). However, there were no significant relationships between packaging color (-0.054) and packaging materials (0.016) in the purchase decision of the cereal packaged food. Ethiopian consumers do not give weight to packaging color and the quality of the packaging material. The findings of this survey will be used to make recommendations to marketers to enhance their level of insight about consumers buying decisions. However, there were no significant relationships between packaging color and packaging materials in the purchase decision of the cereal packaged food.
\end{abstract}

Keywords: package attributes, consumer buying descion behavior

\section{Introduction}

Packaging has long been recognized as the silent salesperson and has been the focus of much recent regulation. For the most part, however, this regulation ignores the nonverbal package label components. The verbal elements of a package are accurate reflections of the product's characteristics. Package, graphics, however, can be used to strengthen or weaken the marketer's explicit verbal claims or to generate inferences that could conflict with the verbal information (Bone \& France, 2001). Package design attributes like color, shape, pictures etc. carry a message about the product as well. Maybe this nonverbal message is an undercover one but not less important. During the last decades in food consumption have been observed several trends that have to do with changes in social and economic environment as well as in lifestyle. The working patterns, the increased employment of women, the lack of time, the income growth and several other factors led to the trend for fast food, convenience foods and food out of home (Petzoldt, Joiko, \& Menrad, 2008).

Packaged food is an indispensable component in the modern lifestyle due to the greater demand for convenient, portable, easy-to-prepare meal solutions that lessen the hassles of grocery shopping and preparing a meal. However, various local food products such as Ethiopian cookies, popcorn, Kollo etc. in Ethiopia lack adequate packaging. In such situation, innovation in packaging becomes a fundamental strategy for competitive success and survival within a competitive market. An innovative packaging design can change product perception and create a new market position (Rundh, 2005). A good packaging design is regarded as an essential part of successful business practice. The reason many companies invest massive amount of money on packaging is because they are well aware that a stunning packaging will draw consumer's attention and is capable of turning the buyer on or off. Packaging is a communication device providing details about the product, including price, contents, ingredients and nutritional values as well as cooking instructions and recommended used by dates (Ahmed, Ahmed, \& Salman, 2005)

Package layout is important for information presentation. However, packaging information can create confusion 
by conveying either too much information or misleading and inaccurate information (Silayoi \& Speece, 2007). To maximize the information carried on products, manufacturers often use very small fonts and very dense writing styles. This reduces readability and sometimes causes confusion. To overcome this problem food industry and the regulation authorities have suggested that nutritional information panels should be laid out in the same way for all food products so that they are easy to understand quickly.

The government of Ethiopia imposed a legislative pressure that affect packaging which is related to labeling whereby the manufacturer or packer is required to declare the nutritional facts, added ingredients, and best-before date criteria on the packaged food to ensure that information on the packaging is sufficient to facilitate the consumers in making purchase decision (Regulation No. 299/2013). Therefore, to ensure success, marketers must not only optimize the visibility of the packaging but also ensure that the packaging is able to communicate the specific benefits of the product and facilitate the consumers in product selection within a variety of brands available in the market.

This study is critically important due to the absence of well-organized studies with respect to the role of packaging attributes on consumer buying behavior on cereal foods in Ethiopia. Moreover, it is important to notice that the Ethiopian environment is different from the developed countries environment where the usage of packaging foods habits. Therefore, this study will be able to bridge the contextual gap in Ethiopia.

\section{Statement of the Problem}

Package attracts consumer's attention to particular brand, enhances its image, and influences consumer's perceptions about product (Rundh, 2005). Moreover, package imparts unique value to products, works as a tool for differentiation, i.e., helps consumers to choose the product from wide range of similar products, stimulates customers buying behavior (Underwood, Klein, \& Burke, 2001; Silayoi \& Speece, 2004). Mohd et al. (2010) and Mallinckrodt \& Mizerski (2007) have concluded that perceived value has significantly influenced the purchasing intention of food products and that consumer brand preferences guide their future behaviors.

Despite the increase in point-of-purchase decisions heightening the communication potential of food product packaging, empirical research works on understanding whether packaging attributes create consumers' subsequent product and brand evaluations and perceptions is scant (Edward et al., 2013). In addition, studies have shown that there is no agreement on classification of package attributes. Some of researchers try to investigate all possible elements of package and their impact on consumer's purchase decision (Silayoi \& Speece, 2004; Silayoi \& Speece, 2007; Butkeviciene, Stravinskiene, \& Rutelione, 2008), while others concentrate on separate elements of package and their influence on consumers buying behavior (Madden, Hewett, \& Roth, 2000; Underwood et al., 2001; Bloch, 1995). Moreover, some researchers investigate impact of package and its elements on consumer's overall purchase decision (e.g., Underwood et al., 2001), while others —on every stage of consumer's decision making process (e.g., Butkeviciene et al., 2008).

Because the abundance of scientific literature on this issue do not provide unanimous answer concerning package elements as well as whether packaging attributes affect consumers buying decisions as well as generate consumers' subsequent product and brand evaluations and perceptions, exploring important packaging elements and the relationship between consumers' attitude towards packaging attributes and product/brand perceptions can provide insights for food firms to enhance consumer-perceived product value and brand preference towards their products using packaging attributes. Finally, to the researcher's knowledge undertaken in a systematized and organized manner in this country. there is no research done on packaging attributed This study therefore, seeks to empirically reveal important elements of packaging and to examine their relationships with the consumers buying decisions in the case of fruit juice products.

\section{Literature Review}

Consumers today are faced with an ever-increasing number of products. According to Belch \& Belch (1999), the average American supermarket holds approximately 20,000 products that are competing to attract the consumers' attention. Keller (2008) expresses a similar opinion when he states that consumers are faced with more than 20,000 choices within a 30-minute shopping session. With so many options available just before a purchase decision is made, the product packaging is one of the best marketing tools companies can use to sell products.

According to MilicaMormann, one of the authors of the study, "the big idea here is that perceptual processes happens in the brain in parallel with economic value computations and thus influence how economic decisions are made." packaging elements: packaging color; background image; packaging material; font style; design of wrapper; printed information and innovation.

According to Nilson \& Ostrom (2005), the product packaging design includes the brand name, color, typography 
and images, all of which influence how quickly and easily a product catches the eye. The visual elements of packaging have a stronger influence on the purchasing when consumers have low involvement in the purchase, in other words, when the product is of low risk and less expensive. They also have a strong impact on impulse purchases.

\subsection{Packaging Attributes}

Packaging elements are Packaging color, Packaging Image, Packaging Material, Font Style of Packaging, Printed Information and Innovation are explained briefly below:

Packaging color: Marketing literature reveals that package colors have the ability to evoke feelings, emotions behaviors in different consumers (Mutsikiwa et al., 2013; White \& White, 2006). The colors have the potential to create a deep and long-lasting impression and image about the product or brand. In the packaging of products, marketers use colors to catch the customers" attention which in turn creates either a negative or positive feeling about the particular product/brand. Asadhollahi \& Givee (2007) suggest that the package colors communicate, reflect and exhibit some salient features and intangible attributes of the brand. It therefore means that the colors convey special messages about the brands which ultimately create a unique selling proposition. However, it is important to note that, in packaging food products, the package colors usually take the colors of the actual product.

Background-image: Underwood (2003) suggest that the product package typography affect the brand identity and personality due to multiple structural and visual elements, including brand logo(s), colors, fonts, package materials, pictorials, product descriptions, shapes and other elements providing rich brand associations. Legibility and readability of the product package are critical concepts of the product typography mostly because, when products are displayed in the shelf, the rationale for package typography is to reduce time spent looking for the particular brand, by ensuring the customer easily locates, identify and notices their preferred brand. Therefore, marketers believe that the brand name, company name, place of origin, company address and others are important components of the package typography which are essential in attracting consumerse ${ }^{\text {e }}$ attention and ultimately influence their purchase decisions.

Packaging Material: Some packaging materials are to be made in a way, so that it could bear the temperature below zero or high temperatures in microwave depending on the product functionalities and the needs of a consumer (Smith, 2004). In one study on food packaging (Lynsey Hollywood, 2013) three packaging materials were discussed which includes glass, plastic, and cardboard. Findings of the research revealed different perceptions of packaging about different packaging materials. Many advocated the use of glass packaging material in food packaging, but then said that it was heavy and it used to be washed after it is used. Secondly, with regard to cardboard packaging consumers had negative views about it and they said that this type of packaging does not keep a product fresh and one also cannot see the product and they referred this kind of packaging to UHT treated food (Lynsey Hollywood, 2013). Participants in that study advocated the use of plastic containers and agreed that such containers were better than cardboard and glass packaging because their screw top cap prevented the product and were less likely to leak (Lynsey Hollywood, 2013).

Font Style: Font is important element of packaging which attracts the customer attention. Packaging information can create contrary results. It can lead to misleading or inaccurate information through small fronts and dense writing styles which are used on the package (Deliya, Parmar, \& others, 2012). Packaging font size is one of the main visual attributes when making a purchase decision (Kuvykaite et al., 2009). The packaging size is related to usability, as consumers appear to use this visual criterion as a heuristic that helps to make volume judgments (Silayoi \& Speece, 2004). Consumers use the height of the container or its elongation to simplify volume judgments (Raghubir \& Krishna, 1999). A bigger package reflects better value but consumers from smaller households are not interested in larger packages (Silayoi \& Speece, 2004). The larger packaging size is more easily noticed and communicates higher value according to Silayoi \& Speece (2004). The font style of Packaging grabs customer attraction. The up gradation of IT technology has support this feature. The successful companies have best practices of the font styles. They hire specialist in composing which create mind blowing and attractive font styles. The attractive package has innovative font style. So, we can say that there is relation between font style and buying behavior.

Printed Information: Packaging as the primary vehicle for communication with the consumer provides details about the product at the point of sales including the nutritional value, added ingredients, country of origin, the producer and best before date. Informational elements of the package play a vital role in decision-making (Silayoi \& Speece, 2004, 2007; Rita, 2009; Kuvykaite et al., 2009). Appropriately delivered information on the packaging has a strong impact on consumer purchase decisions, as this information reduces uncertainty and 
creates product credibility (Silayoi \& Speece, 2004). Consumers are becoming more careful shoppers, and have been found to be paying more attention to label information as well as using the packaging information more extensively, as they are more health and nutrition conscious (Coulson, 2000). The packaging may be the only communication between a product and the consumer in the store (Gonzalez, Thorhsbury, \& Twede, 2007) and is the critical factor in consumer purchase decisions (Butkeviciene, Stravinskiene, \& Rutelione, 2008).

Innovation: Silayoi \& Speece (2004) highlight that technology developed for packaging comes from the current trends in products and consumer behaviors. Packaging innovation in this dynamic environment must be consumer oriented, meet the green marketing agenda, meet the nutritional requirements of the society, must be efficiently manufactured, and should have a long shelf life and meet food safety requirements of the people. Silayoi \& Speece (2004) are of the view that technology that comes in with a package plays a big role and thus forms a special form of informational element. Deliya \& Parmar (2012) are of the view that innovative packaging increases the value of the goods if it meets a consumer needs. In most instance customers accept a product if its package is well innovated, thus product innovation plays a pivotal role in consumer decision making of FMCG products. As part of product innovation font style is also important. Deliya \& Parmar (2012) affirm that font style of packaging grabs customer attraction.

\subsection{Consumer Buying Behavior}

Schiffman \& Kanuk (1997, p. 648) define consumer behavior as: "The behavior that consumers display in searching for, purchasing, using, evaluating, and disposing of products, services, and ideas." Schiffman \& Kanuk (1997, pp. 6-7) elaborate on the definition by explaining that consumer behavior is, therefore, the study of how individuals make decisions to spend their available resources (time, money, effort) on consumption-related items.

Belch \& Belch (2002) define consumer behavior as a set of the activities that a consumer experience in searching for better prospects and this involves namely; searching for, selecting, purchasing, using, evaluating the product. It can also be a process undertaken by consumers to select, purchase, use, or dispose products, services, ideas, or experiences to satisfy their quest. Consumer behavior generally means the behavior of consumer as they look for the product that they feel will satisfy their intended needs and wants. Vila et al. (2007) classified factors considered in consumer purchasing habit into those that can be controlled and those that cannot be controlled. Controllable factors include mainly the 4Ps whilst uncontrollable factors encompass demographic, socio economic, cultural, geographical and psychological factors. Purchase decisions Everyday consumers are faced with purchase decisions. Not all purchase decisions are treated in the same manner because some decisions are more complex than others and therefore call for more effort by the consumer. Yet other decisions are routine and require little effort (Schiffman, Kanuk, \& Hansen, 2008). The term decision entails the selection of an option from at least two alternative brand choices. Regardless of the varying decision-making situations and the levels of consumer decision-making the following factors influence the purchase decisions of consumers. These factors include external (culture, subculture, groups, situation, social class and family; internal (perception, attitude, knowledge, personality, lifestyle, involvement and roles) and marketing factors (product, package aesthetics, promotion, distribution, service and price).

In view of Rita (2009) a good package should be characterized by the following: Attractiveness: the package should be attractive and fascinating to draw customer's attention. Attractive packaging stimulates; thus, packaging can dramatically influence customers' minds hence some end up demanding the product due to its attractive package. Economical: A good package should be economical. Costly package increases the price of the purchased component. Protective: A product should be packaged neatly so that quality, quantity and color of the components does not decline thus it should be insulated from damage by rain, dust or insects. Proper package should ensure no damage or spillage during transportation. Communicative: A good package should provide information about quantity and brand utility of the merchandise. Convenient: The package should allow free and easy movement of the product from one place to another. The shape and package size should also be compatible with retailers and wholesalers for shop or for consumers to keep at home. The package should preferably be re-usable. A good packaging should reflect the conditions in which the product should be sold. Packaging needs to highlight compelling and believable claims on product differences. Prior research studies on packaging attributes in different countries are summarized hereinunder.

KritiBardhan Gupta (2009) has study on Consumer Behavior for Food Products in India. Primary data was collected from 326 respondents in Uttar Pradesh and National Capital Region The relative importance of various food purchasing criteria was estimated for four different food categories, food and vegetables; milk and milk products; food grains and pulses; and processed foods on 1-5 scale. The present study explored the consumer behavior for food products in India from different perspectives. People accepted the fact that their food habits get 
affected with the shifting to a new region but many basic buying and consumption behavior do not change. Some of the changes in buying and consumption behavior of relocated people, which were observed after their settlement to a new region, were not significantly different from the level of changes in behavior of non-moving people. However, compared to the last 10 years, people have started preferring healthier foods and are willing to try out new dishes. They tend to learn cooking and eating new food items after relocation without discontinuing their traditional food items. There is also influence of children on the type of food items that they eat. This paper has shown that impulse buying is indeed a relevant factor in CE retailing, thus justifying the use of sales packaging. However, optimization is still important. From an economical and environmental perspective, it is very costly to apply sales packaging (with additional material use and transport volume) to products that do not need them, or to apply them in an ineffective way. Economical costs and environmental impact can be expressed in a single score, indicating the packs performance. To allow proper management of the pack design the sales performance should be expressed in a simple a way as possible, preferably also a single score. As calculating the sales performance is impossible a test will need to be used. The pressure from time-to-market in the CE industry, demands that the test be relatively simple.

Ahasanul \& Ali (2009) measured the Factors Influencing Buying Behavior of Piracy Impact to Malaysian. A structured questionnaire was used to collect data whereby it was served as primary data to answer the research questions and objectives planning to find out the factors that plays a vital role about consumer's perception towards pirated products. It can be identified that the dependent variable is consumer perception on piracy. Where else the independent variables would be divided to social influence, personality/believe, culture, and the economy. These are the factors that could influence consumers' perception on piracy thereby supporting out dependent variable. Social influence would include susceptibility, which means an individual might purchase a pirated product merely because his/ her friend or family members bought the product and introduced it to them.

Bed Nath Sharma Dec. (2008) studied New Consumer Products Branding, Packaging and Labeling in Nepal. This paper focuses on existing practice of branding, packaging and labeling of new products in consumer product manufacturing units. The study method was Descriptive presentation of facts collected through questionnaire survey concerned with different section of consumer new products (soap, biscuit, noodles, cigarettes and the study further investigates the new consumer product packaging and labeling status in manufacturing units. They are aware about the value of packaging and labeling. Majority of the consumer products $84.37 \%$ ( 27 out of 32 responses) are using product label as a simple tag attached to the product or an elaborately designed graphic that is part of the package.

Nuntasaree \& Barry (2008) published a paper with subject of a model of male and consumer behavior in buying skin care products in Thailand. The conceptual model of male consumer behavior in buying skin care products beliefs in product attributes Quality, Price, Brand, Packaging, Advertising, Promotion, Salesperson, Distribution. This study used a quantitative research method. A convenience sample with a shopping mall-intercept technique was employed for the sampling method. The closed-ended questionnaire developed from standard questions of relevant literature was chosen as a research instrument. The Statistical Package for the Social Sciences program (SPSS) SPSS version 17 was used in this study with a 0.05 level of significance for all of the statistical assessments. The data set was screened and examined for incorrect data entry, missing values, normality and outliers.

Sony (2008) studied the consumer responses toward attribute framing in product packaging. The main purpose of this study was to investigate the impact of message framing, level of involvement, and numerical difference on consumer response. Fresh-milk product was chosen as the object for experiment. This study has the following suggestion for packaging design based on the findings. Fresh milk is commonly considered as health-related product. The study is advantageous in giving marketers a more thorough picture of how message framing affects consumer response in various numerical alternatives and level of involvement. It will also be helpful in developing successful packaging strategy. For future study, different types of products can be investigated further.

\section{Research Questions}

The particular research questions that this study will try to answer includes:

- What are the packaging attributes of cereal food product?

- Is there a significance relationship between packaging of cereal foods attributes and consumer buying decision?

- Which of these attributes significantly affect consumer buying decision in the case of cereal foods? 
- Is there any significance effect of packaging on consumer buying decision?

\section{Conceptual Framework and Hypothesis of the Research}

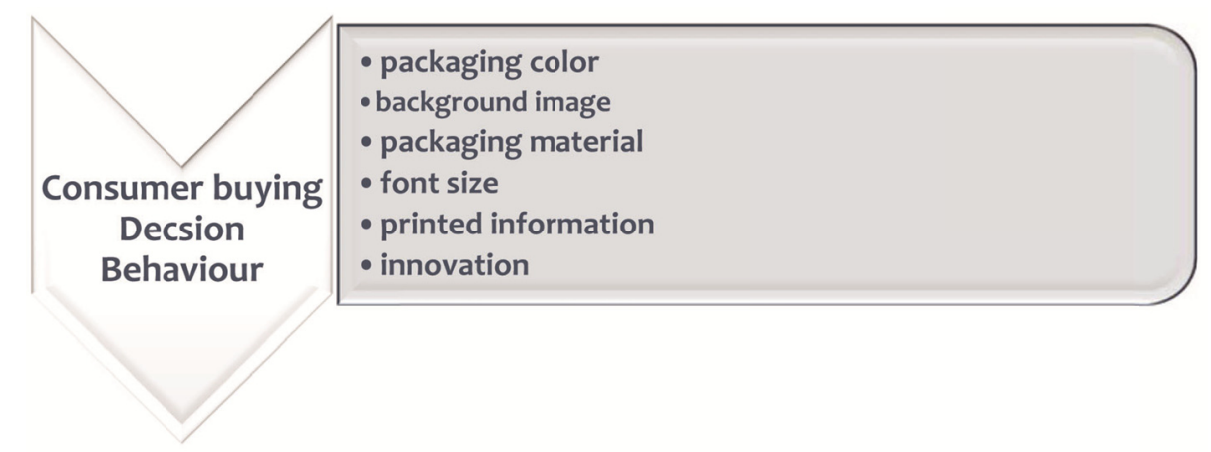

Source: adapted from (Silayoi \& Speece, 2004, 2007).

The following hypotheses were formulated to be tested using appropriate statistical tools.

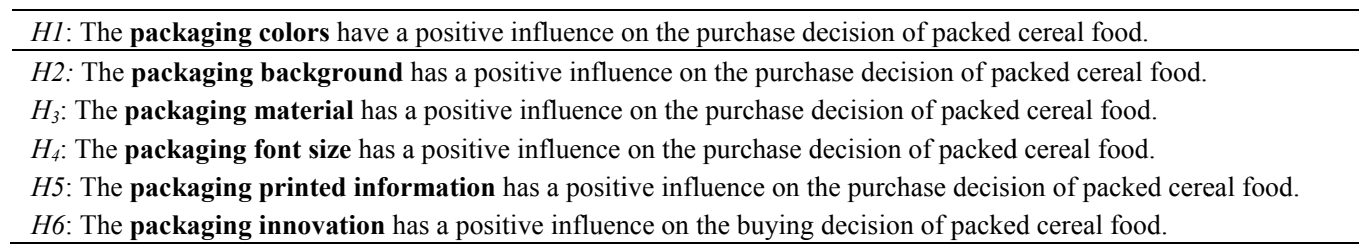

\section{Scope of the Study}

This study is delimited to six major commercial cities in Ethiopia where supermarkets are expanding dramatically in recent years. The study units are all supermarkets operating in the country. The major cities included Addis Ababa, Bahir Dar, Gondar, Hawassa, Nathreth and Dire Dawa. The variables under this study are delimited to packaging color, background image, packaging material, font size, printed information and innovation of the packaging of cereal products. Methodologically, it is delimited to survey only. The study covers both locally manufactured food items as well as internationally branded cereal packed products.

\section{Research Method}

\subsection{Population of the of the Study}

The research focuses on cereal packaging and consumer buying behavior. Consequently, the population for the research consists of all consumers who use packed cereal products in selected supermarkets in the capital city of Ethiopia.

\subsection{Sampling Technique and Sample Size}

The research employed purposive sampling to identify major commercial cities to undertake the survey. In each commercial city, the list of standardized supermarkets was obtained from the chamber of commerce and sectoral association offices. Then, stratified proportional sampling techniques was employed to compute the sample size break down of each commercial city in relation to the aggregate samples size (384) to be considered in this study. Finally, Convenience sampling method was used in all standard supermarkets to contact each customer.

A total of 384 questionnaires were distributed, only 369 questionnaires were returned at the end of the data collection process, which gave the response rate of 96 per cent. However, during the data cleaning only 362 were usable and used for the subsequent statistical analysis. In order to qualify; respondents were asked whether they have bought at least three times from the selected supermarkets and discount stores in the last six months.

\subsection{Data Analysis Method}

Data was analyzed using Correlation to determine the relationship between packaging attributes and consumer buying decision behavior. Regression analysis was also used to determine the predictive value of six packing attributes and consumer buying decision behavior respectively. 


\section{Results and Discussion}

\subsection{Demographic Profile}

The demographic profile of the respondents is shown in Table 1. Out of the 362 respondents, 64.6 per cent are male and 35.4 per cent are female. The age ranges of the respondents are: below 20-30 (36.5\%), 30-40 (49.2\%), $40-50(9.4 \%)$ and above $50(5 \%) .46 .4$ per cent of the respondents are single while 51.7 per cent are married and the balance 1.9 per cent are divorced. With respect to education level, the majority of the respondents are bachelor-degree holders (79.8\%), 20.2 per cent masters-degree holders.

Table 1. Profile of respondents

\begin{tabular}{llll}
\hline Item & Description & Frequency & $\mathbf{\%}$ \\
\hline \multirow{2}{*}{ Gender } & Female & 128 & 35.4 \\
& Male & 234 & 64.6 \\
\multirow{4}{*}{ Age } & 20 to 30 & 132 & 36.5 \\
& 30 to 40 & 178 & 49.2 \\
& 40 to 50 & 34 & 9.4 \\
\multirow{2}{*}{ Marital Status } & Above 50 & 18 & 5.0 \\
& Single & 168 & 46.4 \\
\multirow{2}{*}{ Educational Level } & Married & 187 & 51.7 \\
& Divorced & 7 & 1.9 \\
Do you packed cereal food? & Bachelor's Degree & 289 & 79.8 \\
& Master's Degree & 73 & 20.2 \\
& Yes & 262 & 72.4 \\
& No & 100 & 27.6 \\
\hline
\end{tabular}

In addition, majority of respondent's 72.4 percent agreed to buy packed cereal food while 27.6 percent were declined to be packed cereal food.

\subsection{Reliability Analysis}

Reliability analysis and factor analysis were conducted prior to the regression analysis in order to identify the appropriate items for the analysis. The consistency reliability and the value of Cronbach's alpha will determine the variables' reliability and measure the consistency of a multiple item scale (Sekaran, 2003). Table 2 shows the summary of the reliability analysis and factor loadings for all the measurement items used in multiple regression analysis. Therefore, Cronbach alpha coefficients are above 0.6 which 0.899 demonstrating good internal consistence.

Table 2. Reliability statistics

\begin{tabular}{ll}
\hline Cronbach's Alpha & N of Items \\
\hline 0.899 & 31 \\
\hline
\end{tabular}

\subsection{Over All Mean Score of the Six Attributes of Packaging}

To perform correlation and linear regression analysis on the data, the researcher has created an index for each of the constructs or variables that represent the value of the construct by averaging the subject responses to items.

Table 3. Mean and standard deviation for packaging attributes and consumer buying decision

\begin{tabular}{llllll}
\hline Descriptive Statistics & \multicolumn{7}{l}{} \\
\hline & $\mathrm{N}$ & Minimum & Maximum & Mean & Std. Deviation \\
Consumer buying decision & 362 & 2 & 5 & 4.35 & .618 \\
Packaging color & 362 & 2 & 5 & 3.51 & .721 \\
Background image & 362 & 2 & 5 & 3.81 & .607 \\
Packaging Material & 362 & 2 & 5 & 3.75 & .742 \\
Font Size & 362 & 2 & 5 & 3.56 & .600 \\
Printed Information & 362 & 3 & 5 & 4.10 & .539 \\
Innovation & 362 & 2 & 5 & 3.85 & .564 \\
\hline
\end{tabular}


Table 3 indicates that printed information has the highest mean value of 4.10 and packaging color has the least mean value of 3.51. Therefore, it is concluded from the above table that respondents were concerned with printed information on packed cereal food with a mean score of 4.10. Consumers were less attracted to with packaging color, font size and packaging material at a mean of, 3.51, 3.56 and 3.75, respectively. On the upside, the overall consumer buying decision is recorded the highest mean score of 4.35 that implies consumer showed an interest to buy packed cereal food.

\subsection{Correlation Analysis}

To determine the relationship between packaging attribute (packaging color, background image, packaging material, font size, printed information and innovation) and consumer buying decision, Pearson correlation was computed. Table 4 below presents the results of Pearson correlation on the relationship between packaging attributes and consumer buying decision on cereal packed food.

Table 4. The relationship between packaging attribute and consumer buying decision

\begin{tabular}{|c|c|c|c|c|c|c|c|c|}
\hline \multicolumn{9}{|l|}{ Correlations } \\
\hline & & $\begin{array}{l}\text { consumer buying } \\
\text { decision }\end{array}$ & $\begin{array}{l}\text { Packaging } \\
\text { color }\end{array}$ & $\begin{array}{l}\text { Back } \\
\text { ground image }\end{array}$ & $\begin{array}{l}\text { Packaging } \\
\text { material }\end{array}$ & $\begin{array}{l}\text { Font } \\
\text { size }\end{array}$ & $\begin{array}{l}\text { Printed } \\
\text { information }\end{array}$ & Innovation \\
\hline \multirow{2}{*}{$\begin{array}{l}\text { Consumer } \\
\text { buying decision }\end{array}$} & Pearson Correlation & 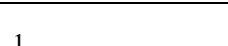 & & & & & & \\
\hline & Sig. (2-tailed) & 1 & & & & & & \\
\hline \multirow{2}{*}{ Packaging color } & Pearson Correlation & $.314^{* *}$ & 1 & & & & & \\
\hline & Sig. (2-tailed) & .000 & & & & & & \\
\hline \multirow{2}{*}{$\begin{array}{l}\text { Background } \\
\text { image }\end{array}$} & Pearson Correlation & $.468^{* *}$ & $.480^{* *}$ & 1 & & & & \\
\hline & Sig. (2-tailed) & .000 & .000 & & & & & \\
\hline \multirow{2}{*}{$\begin{array}{l}\text { Packaging } \\
\text { material }\end{array}$} & Pearson Correlation & $.357^{* *}$ & $.413^{* *}$ & $.442^{* *}$ & 1 & & & \\
\hline & Sig. (2-tailed) & .000 & .000 & .000 & & & & \\
\hline \multirow{2}{*}{ Font size } & Pearson Correlation & $.441^{* *}$ & $.377^{* *}$ & $.364^{* *}$ & $.339^{* *}$ & 1 & & \\
\hline & Sig. (2-tailed) & .000 & .000 & .000 & .000 & & & \\
\hline \multirow{2}{*}{$\begin{array}{l}\text { Printed } \\
\text { information }\end{array}$} & Pearson Correlation & $.471^{* *}$ & $.244^{* *}$ & $.377^{* *}$ & $.551^{* *}$ & $.380^{* *}$ & 1 & \\
\hline & Sig. (2-tailed) & .000 & .000 & .000 & .000 & .000 & & \\
\hline \multirow{2}{*}{ Innovation } & Pearson Correlation & $.595^{* *}$ & $.434^{* *}$ & $.472^{* *}$ & $.321^{* *}$ & $.393^{* *}$ & $.396^{* *}$ & 1 \\
\hline & Sig. (2-tailed) & .000 & .000 & .000 & .000 & .000 & .000 & \\
\hline $\mathrm{N}$ & & 362 & 362 & 362 & 362 & 362 & 362 & 362 \\
\hline
\end{tabular}

The results in table 4 indicate that, there is positive and significant relationship between all packaging attributes and consumer buying decision. All the six packaging attributes (packaging color, background image, packaging material, font size, printed information and innovation) have strong positive correlation with the dependent variable consumer buying decision and highly significant with $\mathrm{p}<0.01$ and Pearson Correlation value of $\mathrm{r}=$ $0.314, \mathrm{r}=0.468, \mathrm{r}=0.357, \mathrm{r}=0.441, \mathrm{r}=0.471$ and $\mathrm{r}=0.595$ for packaging color, background image, packaging material, font size, printed information and innovation, respectively.

\subsection{Regression Analysis}

Before running the regression analysis, all the assumptions were tested.

Model Specification

$\mathrm{Y}=a+b 1 X 1+b 2 X 2+b 3 X 3+b 4 X 4+\mathrm{b} 5 \mathrm{X} 5+\mathrm{b} 6 \mathrm{X} 6+\mathrm{e}$

Where;

Y: Consumer buying decision behavior

$\mathrm{X}_{1}$ : Packaging color

$\mathrm{X}_{2}$ : Background image

$\mathrm{X}_{3}$ : Packaging material

$\mathrm{X}_{4}$ : Font size

$\mathrm{X}_{5}$ : Printed information

X6: Innovation 


\section{$\mathrm{E}=$ error term}

In its simplest form, regression analysis allows market researchers to analyze relationships between one independent and one dependent variable. In marketing applications, the dependent variable is usually the outcome we care about, while the independent variables are the instruments we have to achieve those outcomes with. It can also help make predictions (Mooi \& Sarstedt, 2011).

Table 5. Regression model for packaging attribute

\begin{tabular}{llllll}
\hline Coefficients $^{\text {a }}$ & \multicolumn{7}{l}{} & & \\
\hline Model & \multicolumn{2}{l}{ Unstandardized Coefficients } & Standardized Coefficients & $\mathrm{t}$ & Sig. \\
& $\mathrm{B}$ & Std. Error & Beta & & \\
\hline (Constant) & .634 & .221 & & 2.865 & .004 \\
Packaging Color & -.046 & .041 & -.054 & -1.120 & .264 \\
Background Image & .171 & .050 & .168 & 3.422 & .001 \\
packaging Material & .013 & .042 & .016 & .312 & .756 \\
Font Size & .172 & .047 & .168 & 3.698 & .000 \\
Printed Information & .221 & .057 & .193 & 3.883 & .000 \\
Innovation & .429 & .053 & .392 & 8.172 & .000 \\
R & 0.682 & & & & \\
R square & 0.465 & & & & \\
Adjusted R Square & 0.456 & & & & \\
-F-Value & 51.52 & & & & \\
\hline a. Dependent Variable: Packaging Attributes heavily influences consumer buying decisions. & \\
\hline
\end{tabular}
Note. $N=362 ; * p<.05, * * p<.01$.

The $R^{2}$ value, 0.465 showed that packaging color, background image, font size, packaging material, printed information and innovation were predicted approximately by 46.5 percent of the variations in consumer purchase decisions for packaged cereal food. It indicates the contribution of packaging color, background image, packaging material, font size, printed information and innovation in explaining variance of purchase decision of cereal food is $45.6 \%$. In cross-sectional designs, values of around 0.30 are common while for exploratory research, using cross-sectional data; values of 0.10 are typical (Mooi \& Sarstedt, 2011). The F value was significant at 0.001; therefore, the goodness of the model was supported.

Table 5 above shows the constant, beta, and significance level of each variable. It indicates that six five variables which are; packaging color, background image, packaging material, font size, printed information and innovation influence Consumer buying decision behavior at $95 \%$ confidence interval with a sig. level of $0.264,0.001,0.756$, $0.000,000$ and 0.000 respectively. As the constant and $\mathrm{b}$ values are known. The model for this regression was:

$$
Y=0.634+-.054 X_{1}+.168 X_{2}+.016 X_{3}+.168 X 4+.193 X 5+.392 X 6+0.05
$$

The model suggests that packaging innovation has the strongest effect on cereal food purchase decision $(0.392)$ followed by printed information (0.193), background image (0.168) and font size (0.168). Therefore, $\mathrm{H}_{6}, \mathrm{H}_{5}, \mathrm{H}_{2}$ and $\mathrm{H}_{4}$ are supported. However, there were no significant relationships between packaging color and packaging materials in the purchase decision of the cereal packaged food. Therefore, hypotheses $H_{1}, H_{3}$, are rejected. Thus, it is conclusive that color, packaging material of packaged cereal food are not the determinants of purchase decision among the respondents. A summary of all the results for the hypothesis testing is shown in Table 5.

As indicated in table 5 the packaging colors have no positive and significant influence on the purchase decision of packed cereal food. Color plays an important role in a potential customer's decision-making process; certain colors set different moods and can help to draw attention. Marketing literature reveals that package colors have the ability to evoke feelings, emotions behaviors in different consumers (Mutsikiwa et.al, 2013, White and White, 2006). The colors have the potential to create a deep and long-lasting impression and image about the product or brand. In the packaging of products, marketers use colors to catch the customers ${ }^{\text {ee }}$ attention which in turn creates either a negative or positive feeling about the particular product/brand. 


\subsection{Hypothesis Testing}

Table 5. Hypothesis testing

\begin{tabular}{ll}
\hline$H 1$ : The packaging colors have a positive influence on the purchase decision of packed cereal food. & Not Supported \\
\hline$H 2$ : The packaging background has a positive influence on the purchase decision of packed cereal food. & Supported \\
$H_{3}$ : The packaging material has a positive influence on the purchase decision of packed cereal food. & Not Supported \\
$H_{4}$ : The packaging font size has a positive influence on the purchase decision of packed cereal food. & Supported \\
H5: The packaging printed information has a positive influence on the purchase decision of packed cereal food. & Supported \\
H6: The packaging innovation has a positive influence on the buying decision of packed cereal food. & Supported \\
\hline
\end{tabular}

Asadhollahi \& Givee (2007) suggest that the package colors communicate, reflect and exhibit some salient features and intangible attributes of the brand. It therefore means that the colors convey special messages about the brands which ultimately create a unique selling proposition. However, it is important to note that, in packaging food products, the package colors usually take the colors of the actual product. There is need for marketers to fully understand and appreciate the different meanings of colors across different cultures and comprehend the interpretation of different color combinations as this is critical when consumers make purchase decisions. In the Ethiopian context packaging color was not given high consideration in the buying decisions of consumers.

In one study on food packaging (Lynsey Hollywood, 2013) three packaging materials were discussed which includes glass, plastic, and cardboard. Findings of the research revealed different perceptions of packaging about different packaging materials. Many advocated the use of glass packaging material in food packaging, but then said that it was heavy and it used to be washed after it is used. Secondly, with regard to cardboard packaging consumers had negative views about it and they said that this type of packaging does not keep a product fresh and one also cannot see the product and they referred this kind of packaging to UHT treated food (Lynsey Hollywood, 2013). Participants in that study advocated the use of plastic containers and agreed that such containers were better than cardboard and glass packaging because their screw top cap prevented the product and were less likely to leak (Lynsey Hollywood, 2013). However, in the Ethiopian context packaging material whether glass, plastic or cardboard has no positive influence on the purchase decision of packed cereal food.

\section{Conclusion}

The paper aimed to contribute to the theoretical understanding of the impact of the packaging on the buying decision of cereal foods in Ethiopia specially Addis Ababa City by examining the six major constructs (packing color, background image, font style, packaging material, printed information, and packing innovation) on cereal food product. Through verbal and pictorial symbols packaging can inform the potential buyers about the content of product, characteristics, proper usage, country of origin, benefits and risks. Packaging innovation has the strongest effect on cereal food purchase decision (0.392) followed by printed information (0.193), background image (0.168) and font size (0.168). This corresponds with Deliya \& Parmar (2012) study which concluded that font style has the least effect as compared to all the package elements. However, there were no significant relationships between packaging color and packaging materials in the purchase decision of the cereal packaged food. There is need for marketers to fully understand and appreciate the different meanings of colors across different cultures and comprehend the interpretation of different color combinations as this is critical when consumers make purchase decisions. People want some innovative creations which attract them and shade a different light towards the brand. Unique packaging has a greater influence on consumer buying behavior. The language used to display the information on the packaging gives consumers the ability to understand the product. Nutritional information presented on the package have higher value to consumers and will affect their buying decision more than any other information displayed. Country of origin and guideline on the preparation process of the product have also positive impacts on the consumers buying decisions. Package could be treated as one of most valuable tool in today's marketing communications in cereal foods, necessitating more detailed analysis of with respect to its impact on consumers buying decision behavior.

\section{Recommendations and Future Research}

Results of research on role of packaging in influencing consumer's buying behavior stipulated following recommendations. Results of research on role of packaging in influencing consumer's buying behavior stipulated following conclusions: The use of poor packaging could result in causing a product failure in the market. It is necessary to set appropriate standards to packaging and to enforce the standards accordingly for better marketing and sales of a product. The researcher believes that packages are should be used as a communication strategy at 
the point of purchase and proper care need to be given to the packaging attributes which result in increased sales and revenue as they influence consumers buying decisions. It should be noted that packaging is not the only factor that influences the consumers buying decisions. Therefore, appropriate marketing techniques should be employed to increase the brand preference of the consumer towards the manufacturers product. The researcher recommends an appropriate level of investment should be made to these attributes will result in a reasonable increment in the revenue of an enterprise as they will influence the consumers buying decisions. It must be noted that enterprises must prioritize between packaging attributes as their effect on the consumer buying behavior is not the same. While some attributes like printed information have higher influence, others attributes like fonts may not have the as much influence as expected. The researcher believes that among the packaging attributes, background image of the packaging and printed information on the packaging will have the most influence on the consumers buying decisions. Packaging color and quality of packaging material do not have a significant contribution on the consumers buying decision behavior further enquiry has to be made using interview or focus group discussion. Food Marketers should give exceptional attention Innovation, Printed information, background image and font size. Easy to store and easy to carry innovative packaging designs will enhance the convenience of the consumer in buying and consuming the product. This will in turn increase the influence consumers buying decision.

The present study has several delimitations. It focuses only on major Ethiopian commercial cities. Future studies could focus on all cities all over the country and if funding is available can extend to horn of Africa country's major cities. Thus, the study can be extended to a national level to check if the findings point towards a cultural or a sub cultural context. Furthermore, the impact of packaging attributes on consumer descion behavior in terms of gender, income, education level and professional group differences can be further explored.

\section{References}

Ahasanul, H. (2009). Factors influencing buying behavior of piracy impact to Malaysian market. International Review of Business Research Papers, 5(2), 383-401.

Ampuero, O., \& Vila, N. (2006). Consumer perceptions of product packaging. The Journal of Consumer Marketing, 23(2), 102-114. https://doi.org/10.1108/07363760610655032

Aziz, A., Nasir, A., \& Ahmed, S. (2005). Critical issues in packaged food business. British Food Journal, 107(10), 760-780. https://doi.org/10.1108/00070700510623531

Bed Nath, S. (2008). New consumer products branding, packaging \& labeling Nepal.

Belch, G. E., \& Belch, M. E. (1991). Advertising and Promotion: An Integrated Marketing Communication Perspective (4th ed). New York: Mc Graw Hill.

Bloch, P. H. (1995). Seeking the ideal form: product design and consumer response. Journal of Marketing, 59(3), 16-29. https://doi.org/10.2307/1252116

Bone, P. F., \& France, K. R. (2001). Package Graphics and Consumer Product Beliefs. Journal of Business and Psychology, 15(3), 467-489. https://doi.org/10.1023/A:1007826818206

Butkeviciene, V., Stravinskiene, J., \& Rutelione, A. (2008). Impact of consumer package communication on consumer decision making process. Inzinerine Ekonomika-Engineering Economics, 1, 57-65.

Coulson, N. S. (2000). An Application of the Stages of Change Model to Consumer Use of Food Labels. British Food Journal, 102(9), 661-668. https://doi.org/10.1108/00070700010362031

Deliya, M. M., \& Bhaveshkumar, P. (2012). Role of Packaging on Consumer Buying Behavior-Patan District. Global Journal of Management and Business Research, 12(10).

Edward, S. T. W. (2013). The influence of visual packaging design on perceived food product quality, value, and brand preference. International Journal of Retail \& Distribution Management, 41(10), 805-816. https://doi.org/10.1108/IJRDM-12-2012-0113

Gonzalez, M. P., Thorhsbury, S., \& Twede, D. (2007). Packaging as a tool for product development: Communicating value to consumers. Journal of Food Distribution Research, 38(1), 61-66.

Keller, K. L. (2003). Strategic brand management: Building, measuring and managing brand equity (2nd edition). Englewood Cliffs, NJ: Prentice-Hall

Kotler, P., \& Keller, K. (2011). Marketing Management (14th edition). London: Pearson Education.

Kritibardahan, G. (2009). Consumer behavior for food products India. 
Kuvykaite, R. (2009). Gaminio marketing as. Kaunas: Technologija.

Madden, T. J., Hewett, K., \& Roth, M. S. (2000). Managing images in different cultures: A cross-national study of color meanings and preferences. Journal of International Marketing, 8(4), 90-107. https://doi.org/10.1509/jimk.8.4.90.19795

Mallinckrodt, V., \& Mizerski, D. (2007). The effects of playing an average on young children's perceptions, preferences, and requests. Journal of Advertising, 36(2), 87-100. https://doi.org/10.2753/JOA0091-3367360206

Mohd, R. S., Jacqueline, J. P., Suhardi, W. M., \& Shamsul, J. E. (2010). Purchase intention of organic food; perceived value. Canadian Social Science, 6(1), 70-79.

Nilsson, J., \& Ostrom, T. (2005). Packaging as a Brand Communication Vehicle. Thesis of Lulea University of Technology.

Nuntasaree, S., \& Barry, E. (2008). A model of male consumer behavior in buying skin care products in Thailand. ABAC Journal, 29(1).

Nuntasaree, S., \& Barry, E. (2008). Model of male consumer behavior in skin products Thailand.

Petzoldt, M., Joiko, C., \& Menrad, K. (2008). Factors and their impacts for influencing food quality and safety in the value chains, D4.3, University of Applied Science Weihenstephan-AG2020. Regulation No. 299/2013", Negarit Gazetta, FDRE.

Rita, K. (2009). Impact of package elements on consumer purchase, Kauno technologijos universities, Lietuva, ekonomika is vadyba.

Rundh, B. (2005). The multi-faceted dimension of packaging. British Food Journal, 107(9), 670-684. https://doi.org/10.1108/00070700510615053

Schiffman, L. G., \& Lesile, L. K. (2008). Consumer behavior: A European outlook. New York: Prentice hall

Silayoi, P., \& Speece, M. (2004). Packaging and purchase decisions: a focus group study on the impact of involvement level and time pressure. British Food Journal, 106(8), 607-628. https://doi.org/10.1108/00070700410553602

Silayoi, P., \& Speece, M. (2007). The importance of packaging attributes: a conjoint analysis approach. European Journal of Marketing, 41(11/12), 1495-1517. https://doi.org/10.1108/03090560710821279

Smith, P., \& Taylor, J. (2004), "Marketing communications: an integrated approach (4th edition). London: Kogan Page.

Underwood, R. L. (2003). The communicative power of product packaging: creating brand identity via lived and mediated experience. Journal of Marketing Theory and Practice, winter, 62-76. https://doi.org/10.1080/10696679.2003.11501933

Underwood, R. L., Klein, N. M., \& Burke, R. R. (2001). Packaging communication: attentional effects of product imagery. Journal of Product \& Brand Management, 10(7), 403-422. https://doi.org/10.1108/10610420110410531

Venter, K., van der Merwe, D., de Beer, H., Kempten, E., \& Bosman, M. (2011). Consumers perceptions of food packaging: an exploratory investigation in Potchefstroom, South Africa. International Journal of Consumer Studies, 35(3), 273-281. https://doi.org/10.1111/j.1470-6431.2010.00936.x

Vila, N., \& Ampuero, O. (2007). The role of packaging in positioning an orange juice. Journal of Food Products Marketing, 13(3), 21-48. https://doi.org/10.1300/J038v13n03_02

\section{Copyrights}

Copyright for this article is retained by the author, with first publication rights granted to the journal.

This is an open-access article distributed under the terms and conditions of the Creative Commons Attribution license (http://creativecommons.org/licenses/by/4.0/). 